\title{
T Wave Area Aggregate
}

National Cancer Institute

\section{Source}

National Cancer Institute. T Wave Area Aggregate. NCI Thesaurus. Code C117810.

An aggregate $T$ wave area value based on the measurement of $T$ wave areas from

multiple beats within a single ECG. The method of aggregation, which can vary, is typically

a measure of central tendency such as the mean. (CDISC) 